\title{
A ERGONOMIA E A ARQUITETURA NO CUIDADO DAS PESSOAS COM TRANSTORNO MENTAL
}

\author{
VASCONCELOS, Marina Cordeiro (1); \\ FALCÃO, Christianne Soares (2)
}

(1) Universidade Católica de Pernambuco, Graduanda em Arquitetura e Urbanismo

e-mail: marina-cv@outlook.com

(2) Universidade Católica de Pernambuco, Doutora em Design UFPE

e-mail:christiannefalcao.arq@gmail.com

\begin{abstract}
RESUMO
Em face da complexidade de um diagnóstico de transtorno mental, uma série de mudanças é requerida na dinâmica familiar, cuidados especiais da saúde daquela pessoa, tratamentos medicamentosos, terapias, atenção diferenciada à sua higiene, alimentação e cognição. Contudo, na maioria das vezes o arranjo físico da residência não é considerado como um aspecto a ser adaptado após o diagnóstico. Em face dessa problemática, este artigo tem como objetivo traçar diretrizes para uma adequada análise das condições ambientais e proposta de adaptação conforme as características levantadas. Para tal, buscou-se uma metodologia de investigação baseada nos métodos consolidados da ergonomia e da arquitetura. Como resultado, espera-se contribuir na discussão sobre a importância da inclusão da arquitetura da residência das pessoas com transtorno mental como um dos cuidados especiais, para um melhor desenvolvimento das atividades do cotidiano da família.
\end{abstract}

Palavras chave: ergonomia do ambiente construído; NBR 9050; mapa de riscos.

\begin{abstract}
In face of the complexity of a mental disorder diagnosis, a number of changes are required in family dynamics, special care of that person's health, drug treatments, therapies, differentiated attention to their hygiene, food and cognition. However, most of the time the physical arrangement of the residence is not considered as an aspect to be adapted after the diagnosis. In view of this problem, this article aims to outline guidelines for an adequate analysis of the environmental conditions and proposal of adaptation according to the characteristics raised. For this, an investigation methodology was sought based on the consolidated methods of ergonomics and architecture. As a result, it is hoped to contribute to the discussion about the importance of including the architecture of the residence of people with mental disorder as a special care, for a better development of the daily activities of the family.
\end{abstract}

Keywords: environmental ergonomic; NBR9050; risk map.

\section{INTRODUÇÃO}

Transtornos mentais são mudanças no funcionamento da mente que prejudicam o desempenho da pessoa em qualquer aspecto da sua vida. Seja a forma da pessoa entender a si mesma, o mundo, seu juízo de realidade ou sua noção do perigo. Essas disfunções mentais causam variações de humor, incapacidade de sentir prazer, intolerância aos problemas, dentre outros. Como consequência, o desempenho da vida em sociedade é 
prejudicado, seja na vida familiar, pessoal, no trabalho ou nos estudos (AMARAL et al., 2003). Dependendo do grau do transtorno, pode alterar a sensopercepção, uma das funções psíquicas. Ela engloba os cinco sentidos externos (audição, visão, olfato, paladar e tato), os três sentidos internos (sinestésico, cinético e de orientação) e a consciência. Desse modo, o juízo de realidade da pessoa é alterado, sua noção de perigo e morte fica difusa, e sua percepção da realidade é prejudicada (DALGALARRONDO, 2008).

A origem biológica do transtorno mental ainda é desconhecida e seus conceitos ainda são difusos, visto que não existem células e microrganismos que causem esses males, nem um foco a ser identificado e combatido. Então é nesse cenário que outras disciplinas se inserem e dão suporte para a conceituação e estudo, como a área da comunicação, terapia, educação, entre outros (FREITAS-SILVA; ORTEGA, 2016).

A questão é que as pessoas com transtornos mentais saíram de ambientes próprios para seu tratamento, ainda que fossem ambientes insalubres e hostis, e foram para suas casas com o acolhimento familiar e maior qualidade de vida, porém sem ter o ambiente próprio para seus cuidados especiais. Muitas tarefas cotidianas são extremamente difíceis de serem executadas devido à falta de suporte no ambiente residencial.

Neste cenário, um diagnóstico tão complexo quanto o transtorno mental requer uma série de mudanças na dinâmica familiar, cuidados especiais da saúde daquela pessoa, tratamentos medicamentosos, terapias, atenção diferenciada à sua higiene, alimentação e cognição. Entretanto, a arquitetura de sua residência não tem sido considerada como um desses aspectos a serem adaptados depois do diagnóstico. A falta de atenção para esse quesito é um grande problema nas atividades do cotidiano da família.

$O$ presente estudo tem por finalidade inserir os conceitos da ergonomia e da arquitetura no cuidado das pessoas com transtornos mentais, por meio de recomendações técnicas, buscando medidas de segurança e bem-estar através da adaptação de suas residências. Assim, além do acolhimento familiar e conforto do lar já existente, essas residências teriam o suporte ergonômico de cuidados especiais fazendo parte do conjunto de mudanças necessárias, auxiliando não só na vida das pessoas com transtornos mentais, mas também dos familiares.

\section{CONCEITUAÇÃO TEMÁTICA}

Uma pessoa com transtorno mental que tem a sensopercepção alterada e apresenta um comprometimento na noção da realidade. O controle da força, a percepção do perigo e o entendimento de morte são conceitos extremamente difusos e limitados pelo transtorno. Simples móveis ou utensílios do uso diário podem representar perigos em potencial para pessoas que tem seu juízo de realidade alterado (DALGALARRONDO, 2008). Além do mais, qualquer atividade simples do cotidiano pode ser um grande desafio para os familiares que dão assistência à pessoa com transtorno mental.

$\mathrm{Na}$ atualidade, o Brasil conta com uma Norma Brasileira Regulamentadora (NBR 9050, 2015) de acessibilidade para pessoas com baixa mobilidade, pessoas em cadeira de rodas e com deficiência visual, porém não contempla as peculiaridades do tratar de alguém com transtorno mental, e em alguns pontos, as regulamentações se opõem ao que deveria ser feito para essas pessoas.

Os critérios e parâmetros estabelecidos pela NBR 9050 (2015) foram estabelecidos considerando as "diversas condições de mobilidade e de percepção do ambiente", o que incluiria pessoas com transtorno mental, já que o transtorno altera a percepção do ambiente e, algumas vezes, está atrelado a alguma dificuldade motora. Entretanto, a Norma completa posteriormente tratar apenas pessoas: "... com ou sem a ajuda de aparelhos específicos, como próteses, aparelhos de apoio, cadeiras de rodas, bengalas de rastreamento, sistemas assistivos de audição ou qualquer outro que venha a complementar necessidades 


\section{(x) $^{\text {reace }}$}

individuais." - (NBR 9050, 2015, p. 1).

Dessa forma, a Norma não contempla pessoas com transtornos mentais simplesmente porque não é o seu objetivo. Os parâmetros e critérios não foram feitos para contemplar as peculiaridades e individualidade de pessoas com transtornos mentais. Portanto, a NBR 9050 (2015) apresenta uma lacuna no que diz respeito ao ambiente residencial e recomendações de adaptações para a melhoria do espaço interno da residência de pessoas com transtorno mental.

Porém, alguns dos critérios podem ser aproveitados com os mesmos parâmetros, como altura das barras de seguranças e tamanho do box para o cadeirante, visto que a pessoa com transtorno mental pode não fazer o uso da cadeira de rodas, porém geralmente toma banho com a assistência de um familiar ou cuidador. $O$ espaço que a cadeira faria o giro seria ocupado pelo familiar ou cuidador que auxilia a pessoa com transtorno mental e o banco sugerido seria ótimo para evitar acidentes e facilitar o banho.

Outra opção de norma aplicável ao presente estudo corresponde a Norma Regulamentadora 9 (NR 9, 1978), cuja abordagem está direcionada a segurança do trabalho, prevenção de saúde e da integridade física do trabalhador. A NR explica, define e ensina a elaborar um Mapa de Riscos, que consiste numa planta baixa do ambiente de trabalho que indica os tipos de riscos que um funcionário está exposto dentro de um determinado ambiente, e ainda diz qual a intensidade desse risco e quantos funcionários estão expostos.

O mapa de riscos foi adaptado neste estudo para o âmbito residencial. A importância da criação desse mapa se dá pela alteração do juízo de realidade da pessoa com transtorno mental, visto que ela não identifica os riscos e qualquer objeto ao seu redor pode se tornar um agente causador de acidentes.

\section{PROCEDIMENTOS METODOLÓGICOS}

Para que os objetivos deste estudo fossem atingidos, como primeira etapa foi realizada uma revisão de literatura para uma melhor compreensão do contexto da pessoa com transtorno mental, assim como as normas que se aplicam a este contexto. Na segunda etapa foi realizada uma Análise do Ambiente Construído com base nos conceitos abordados em Falcão e Soares (2011) e Bastos (2015), no ambiente residencial de três famílias que possuíam um dos membros com algum tipo de transtorno mental.

As inadequações na residência foram investigadas através de entrevistas e vivência com os familiares, no intuito de entender as atividades e a dinâmica da casa, para mostrar a importância da inserção da ergonomia e arquitetura no processo de cuidado da pessoa com transtorno mental e de como um arranjo físico inadequado dificulta o dia a dia da família. Foi feito um mapeamento das dificuldades nas atividades diárias em seus respectivos ambientes, apontando os riscos e indicando os usos que a pessoa com transtorno faz em cada ambiente. Foi elaborado um mapa de riscos residenciais segundo a NR9 adaptado ao tema para nortear a intervenção do ambiente interno.

Por fim, as características das atividades foram identificadas, permitindo que diretrizes de projeto sejam traçadas para promover a saúde, o conforto e a segurança da pessoa com transtorno mental e sua família, minimizando os riscos identificados e melhorando a qualidade de vida dos envolvidos.

\section{ESTUDOS DE CASO}

A relação humano-ambiente torna-se bastante complexa a partir da compreensão de que o ambiente é responsável pela parte física e palpável, enquanto o humano é responsável pela parte imaterial, com condicionantes culturais, sociais, econômicos, etc. O ser humano e o ambiente estão em constantes trocas, ajustes e adaptações (BASTOS, 2015). 
Para começar, é imprescindível compreender as necessidades, as sensações e a percepção do indivíduo naquele espaço a ser analisado. Então é necessário agregar valores de muitas disciplinas que funcionam como pilares, dando suporte à análise do ambiente, o design, ergonomia, arquitetura e psicologia ambiental (FALCÃO; SOARES, 2011). Para o presente estudo, foi considerada a conexão do pilar da arquitetura com o pilar da ergonomia.

Desta forma, as análises propostas neste artigo foram realizadas com pessoas que tinham um transtorno mental que gera alteração na sensopercepção do espaço, procurando entender como funciona um ambiente a partir da perspectiva de alguém que não compreende aquele espaço da forma como ele é comumente compreendido. O estudo procurou identificar como o ambiente funciona para aquele indivíduo e como a arquitetura está atrapalhando ou auxiliando no dia a dia daquela pessoa.

Ao se tratar de uma pessoa com transtorno, as atividades são um pouco diferenciadas, dependendo da dinâmica da família. A casa não funciona comumente, os ambientes nem sempre são usados da forma mais usual e cada família lida com essa dinâmica de forma diferente, o que justifica a necessidade da mudança na arquitetura dessa residência. A visita em todas as residências começou com um caminho geral na casa inteira, para poder desenhar um croqui da planta baixa com as divisões dos ambientes. Simultaneamente, os perigos foram identificados enquanto os familiares descreviam o dia a dia e respondiam algumas perguntas.

\subsection{Apreciação dos Riscos}

Segundo Ferreira (2014), a palavra "risco" significa perigo e estar exposto ao perigo. Baseada na Norma Regulamentadora 9 (NR9), elaborou-se um mapa de perigos residencial, que consiste na planta baixa considerando os ambientes de uma residência, com as mesmas nomenclaturas de riscos descritos na NR 9: Risco químico, biológico, físico, de acidentes e ergonômico. Dessa forma, fazendo um paralelo às descrições de cada risco, adaptando para o âmbito residencial, os riscos foram organizados em ordem decrescente de acordo com o grau de perigo em relação à vida das pessoas residentes, conforme ilustrado no Quadro 1.

\section{Quadro 1 - Classificação dos riscos.}

\begin{tabular}{|l|l|}
\hline $\begin{array}{l}\text { Riscos químicos diz respeito ao acesso de substâncias nocivas à saúde caso ingeridas, } \\
\text { manipuladas de forma exagerada ou em contato com os olhos, como perfumes, xampus, água } \\
\text { sanitária, medicamentos, óleo, entre outros. Esse tipo de risco foi classificado como o mais perigoso, } \\
\text { tendo a cor mais escura. }\end{array}$ \\
\hline $\begin{array}{l}\text { Riscos biológicos trata de ambientes que proporcionem de alguma maneira uma contaminação, o } \\
\text { acesso ao lixo, dejetos e esgoto. Esse risco foi classificado como o segundo mais perigoso, tendo cor } \\
\text { um pouco mais clara. }\end{array}$ \\
$\begin{array}{l}\text { Riscos mecânicos são os riscos mais comuns, porém não menos nocivos. São chamados de } \\
\text { acidentes cotidianos, como queimaduras, choques, arranhões em quinas de móveis, tropeços, entre } \\
\text { outros. Foi classificado como um risco de intensidade média, e tem a cor mediana. }\end{array}$ \\
$\begin{array}{l}\text { Riscos ergonômicos inicia a classificação de riscos que não oferecem perigo de morte, mas que } \\
\text { trazem um dano para as pessoas envolvidas. Os riscos ergonômicos são esforço físico pesado, } \\
\text { posturas incorretas ou posições incômodas, repetitividade e interrupção do sono. }\end{array}$ \\
$\begin{array}{l}\text { Riscos físicos são os mais simples e controláveis, como umidade, calor, frio, ruídos, entre outros. } \\
\text { Não trazem nenhum risco de morte, mas interfere na qualidade da vida das pessoas residentes. }\end{array}$ \\
\hline
\end{tabular}

Fonte: Adaptado pelas autoras com base na NR 9 (1978). 


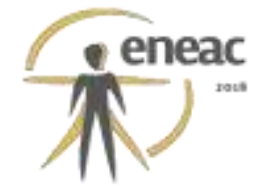

\subsection{Família A}

A família $A$, é composta por três pessoas, sendo elas: o marido, a esposa e o filho de sete anos diagnosticado com autismo aos dois anos de idade. $\mathrm{O}$ apartamento está no terceiro andar, possui oito ambientes bem definidos, poucos móveis, cores claras nas paredes e praticamente nenhum adorno ou objeto de decoração, o que é extremamente importante para o filho com autismo e deixa a casa mais agradável para ele. Nenhum dos móveis do apartamento possui vértices afiados, diminuindo os riscos mecânicos, e todos os cômodos contam com prateleiras altas que armazenam objetos que são nocivos à pessoa com transtorno, principalmente nos banheiros, onde são guardados produtos de higiene pessoal e remédios, o que diminui a possibilidade de risco químico.

A cozinha não possui barreiras para impedir o acesso da pessoa com transtorno, a mãe relatou que ensinou ao filho que aquele ambiente é perigoso e ele respeita esses limites. $O$ único uso que ele faz nesse ambiente é subir em um banco para pegar biscoito no armário, possibilitando um risco ergonômico. A sala de jantar possui um grande vaso de vidro com flores artificiais, possibilitando risco mecânico. As refeições são feitas na mesa e a criança compreende quando está na hora de comer e faz o uso da mesa e cadeira tranquilamente.

$\mathrm{Na}$ sala de estar tem um sofá, um rack e uma televisão em que o filho gosta de assistir filmes e desenhos durante o dia. A varanda possui um varal, alguns brinquedos guardados e a sua bicicleta com rodinhas.

Figura 1 - Mapa de riscos da residência da Família A.

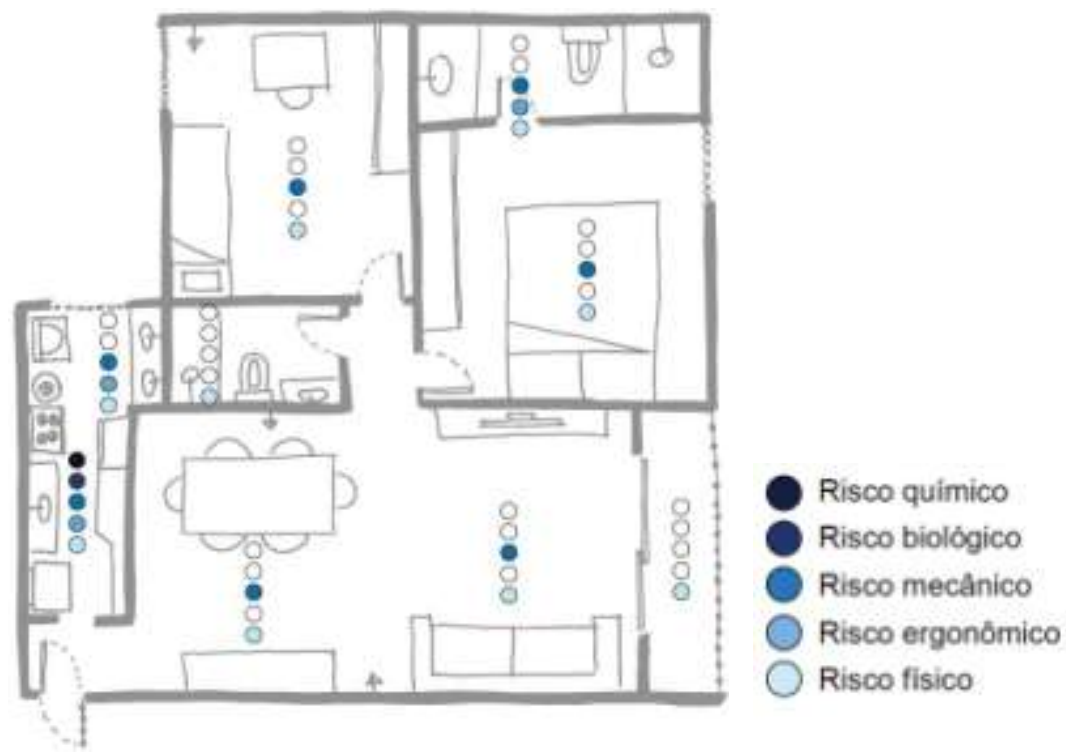

Fonte: Elaborado pelas autoras

O banheiro social funciona como lavabo e a família inteira divide o banheiro da suíte para tomar banho, inclusive, a mãe relatou que sente dificuldade ao dar banho no filho, pois acha o banheiro pequeno, o que ocasiona risco ergonômico para ela. O filho reclama também que a casa é pequena e apertada, mesmo que em dimensões e nos parâmetros normais ela não seja. Então isso causa um desconforto e insatisfação nele, gerando um risco físico.

As janelas dos quartos possuem tela de proteção, a varanda tem um peitoril de grade e tela, e na janela alta da área de serviço tem grade. Essas aberturas possuem cortinas para filtrar a entrada de luz. Existe apenas um espelho na casa, aplicado na porta do guarda roupa do casal, em que o filho gosta de se observar. Porém, é um fator de risco mecânico, visto que a porta é de correr e pode causar um acidente. 


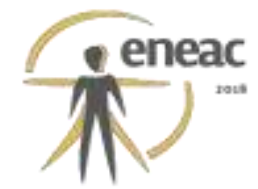

Em seu quarto, ele estuda em uma pequena mesa e cadeira de plástico, onde também mantém seus brinquedos organizados e guardados. A cama fica próxima a janela, onde ele gosta de observar a rua e jogar pequenos aviões de papel que ele mesmo confecciona. Possui também uma rede que ele gosta de se balançar e relaxar.

O único uso que a criança faz na área de serviço é subir em um banco, ficar em pé no tanque de lavar roupa e jogar aviões maiores de papel pela grade. Isso proporciona risco ergonômico e mecânico, mas ao mesmo tempo é uma atividade extremamente importante e relaxante para ele.

Figura 2 - Imagens da residência da Família A (sala, quarto e área de serviço).
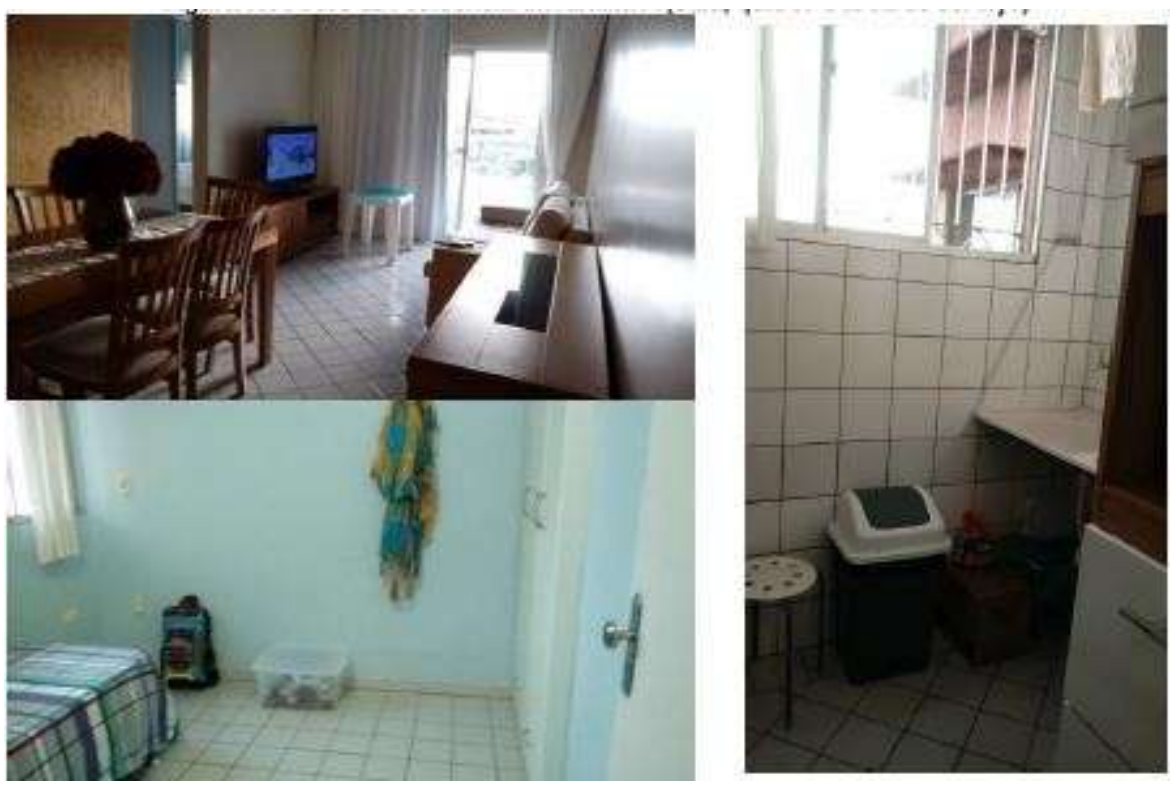

Fonte: Marina Vasconcelos, 2017.

Figura 3 - Mapa das atividades da pessoa com transtorno mental

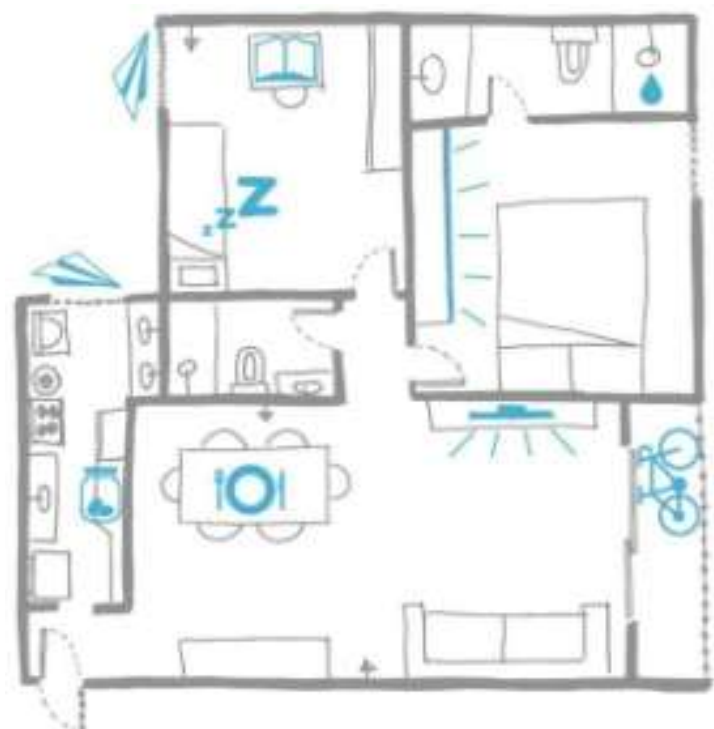

Fonte: Elaborado pelas autoras 
Quadro 2 - Síntese da família A.

\begin{tabular}{|c|c|c|}
\hline AMBIENTE & MOBILIARIO & OBSERVAÇOES \\
\hline $\begin{array}{l}\text { QUARTO } \\
\text { DELE(A) }\end{array}$ & $\begin{array}{l}\text { Cama e guarda roupa } \\
\text { Mesa e cadeira de plástico } \\
\text { Estante alta e rede }\end{array}$ & $\begin{array}{l}\text { Sobe na cama para observar a vista da janela e } \\
\text { jogar aviōes de papel }\end{array}$ \\
\hline $\begin{array}{l}\text { SALADE } \\
\text { ESTAR } \\
\text { E JANTAR }\end{array}$ & $\begin{array}{l}\text { Rack com TV e vaso } \\
\text { Sofá } \\
\text { Mesa de } 6 \text { lugares com vaso } \\
\text { Aparador }\end{array}$ & $\begin{array}{l}\text { Ambos os vasos são de vidro } \\
\text { Passa muito tempo na TV }\end{array}$ \\
\hline $\begin{array}{l}\text { BANHEIRO } \\
\text { SOCIAL }\end{array}$ & $\begin{array}{l}\text { Vaso sanitário e pia } \\
\text { Prateleiras } \\
\text { Box de vidro }\end{array}$ & $\begin{array}{l}\text { Funciona como lavabo e guarda coisas no box. } \\
\text { Tem prateleiras altas para armazenamento de } \\
\text { remédios e produtos de higiene. }\end{array}$ \\
\hline $\begin{array}{l}\text { COZINHAE } \\
\text { AREA DE } \\
\text { SERVIÇO }\end{array}$ & $\begin{array}{l}\text { Geladeira e fogăo } \\
\text { Pia e bancada } \\
\text { Armários } \\
\text { Prateleiras altas } \\
\text { Máquina de lavar e tanque }\end{array}$ & $\begin{array}{l}\text { Sobe na no tanque de lavar roupa para observar a } \\
\text { vista da janela a jogar aviōes de papel. } \\
\text { Sobe no banquinho para pegar biscoitos na } \\
\text { estante. }\end{array}$ \\
\hline $\begin{array}{l}\text { QUARTO } \\
\text { DOS PAIS }\end{array}$ & $\begin{array}{l}\text { Cama de casal } \\
\text { Ar condicionado } \\
\text { Prateleiras altas } \\
\text { Guarda roupa }\end{array}$ & Gosta de se olhar no espelho do guarda roups. \\
\hline $\begin{array}{l}\text { BANHEIRO } \\
\text { DOS PAIS }\end{array}$ & $\begin{array}{l}\text { Vaso sanitário e pia } \\
\text { Prateleiras altas } \\
\text { Box de vidro }\end{array}$ & $\begin{array}{l}\text { Tem prateleiras altas para armazenamento de } \\
\text { remédios a produtos de higiene. Dificuldade ao } \\
\text { dar banho no filho, pois acha o espaço pequeno. }\end{array}$ \\
\hline VARANDA & $\begin{array}{l}\text { Estender roupa } \\
\text { Guardar a bicicleta }\end{array}$ & $\begin{array}{l}\text { Tem grade no peitoril e o restante è completado } \\
\text { com tela de proteçắa. }\end{array}$ \\
\hline
\end{tabular}

Fonte: Elaborado pelas autoras

\subsection{Família B}

A família B é composta por quatro pessoas, sendo elas: o marido, a esposa, o filho mais velho de 19 anos e a filha de 17 anos diagnosticada com autismo aos 2 anos de idade. $O$ apartamento se encontra no térreo de um edifício, possui 13 ambientes e a zona de serviço é fragmentada, tendo pouco espaço para circulação, possibilitando risco mecânico. A casa possui muitos quadros e enfeites como portas retratos, luminárias de mesa e lembrancinhas de viagens, o que pode causar risco mecânico.

A mãe criou a filha com bastante independência, ela usa o computador e celular, toma banho sozinha e auxilia nas atividades domésticas como lavar louça e estender roupa, o que possibilita risco químico, biológico e mecânico. Em situações específicas, ela também fica sozinha em casa enquanto a mãe vai na padaria ou na casa da irmã, que fica na mesma rua.

O lugar preferido dela é seu quarto, onde ela come e fica no computador. O quarto do irmão é outro lugar que ela gosta muito de ficar, assiste o irmão jogar videogame e passa muito tempo com ele. Ela dorme no quarto com os pais devido ao calor, pois a fachada da zona íntima é poente e de tarde fica muito quente. Os pais preferem que ela durma no quarto deles por questões de vigilância também.

A família procura deixar a filha bem à vontade, deixando-a tomar decisões como the convém. Segundo a mãe, ela come no quarto porque prefere, mas se necessário, ela come na mesa tranquilamente. Ela dorme sozinha no quarto também, mas prefere dormir com os pais, e assim sucessivamente.

A adolescente descreveu sua casa como linda, e disse na entrevista que gostava da sua casa. A maior dificuldade da família é em relação à intolerância que ela tem a novidades e mudanças. Sempre que alguém precisa ser contratado para até mesmo consertar algo na casa, ela reclama e implica até que a pessoa vá embora, e demora a ser convencida de que aquela atitude foi para a melhoria da casa. 


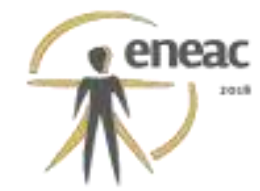

Figura 4 - Mapa de riscos da residência da Família B.

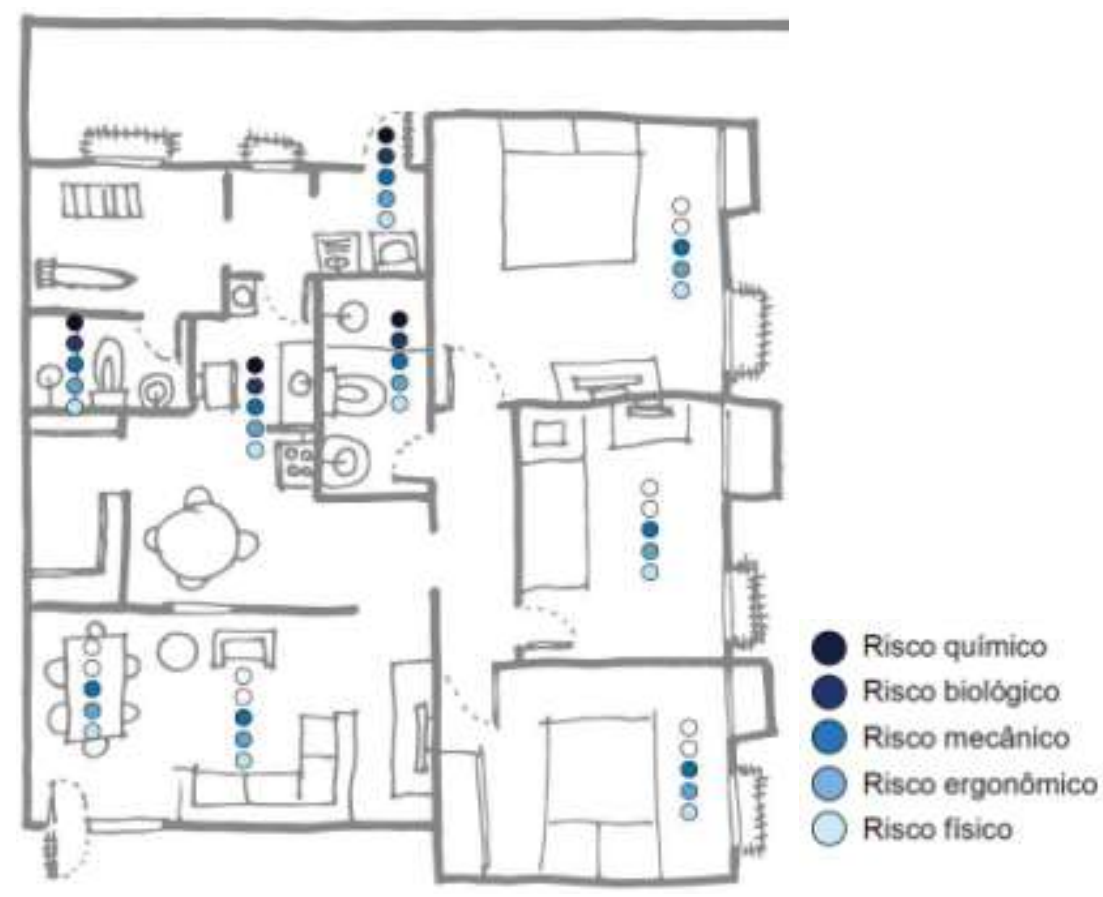

Fonte: Elaborado pelas autoras

Figura 5 - Imagens da residência da Família B (copa, quarto, sala e cozinha).
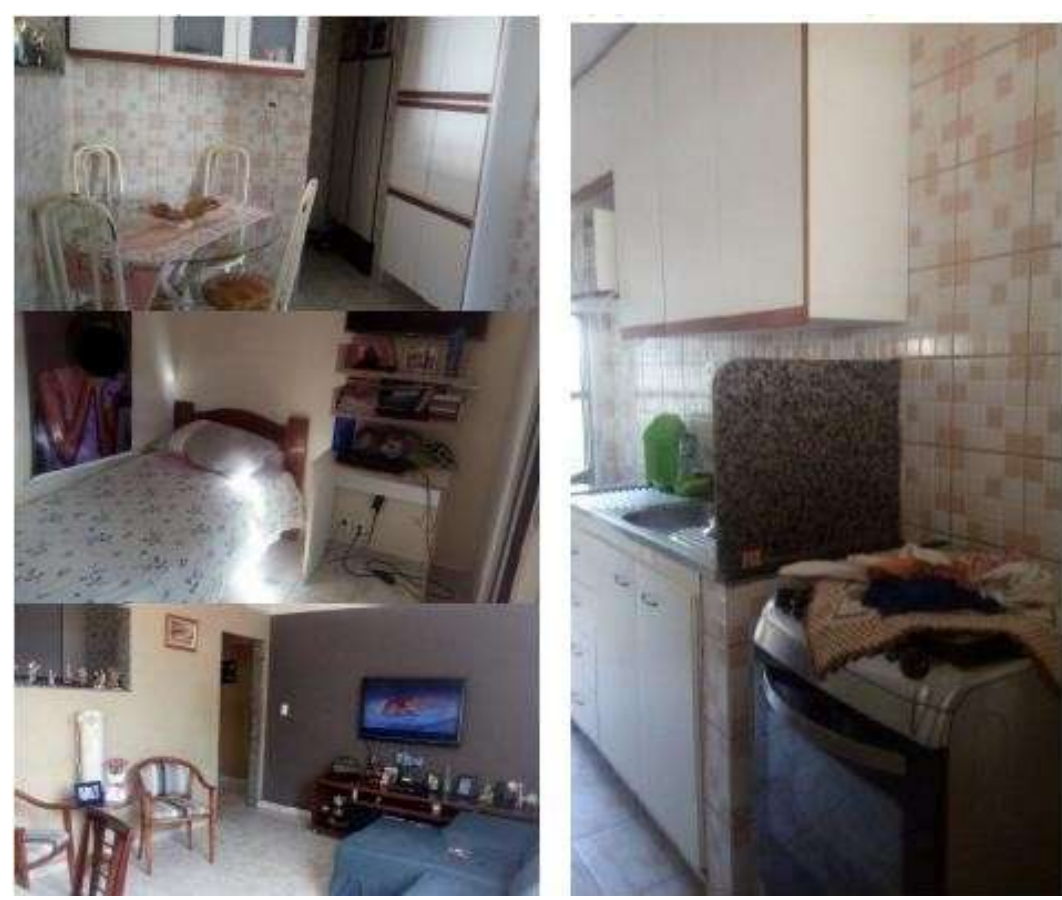

Fonte: Marina Vasconcelos, 2017. 


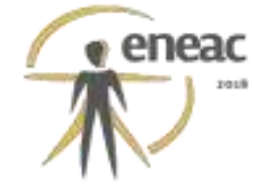

Figura 6 - Mapa das atividades da pessoa com transtorno mental

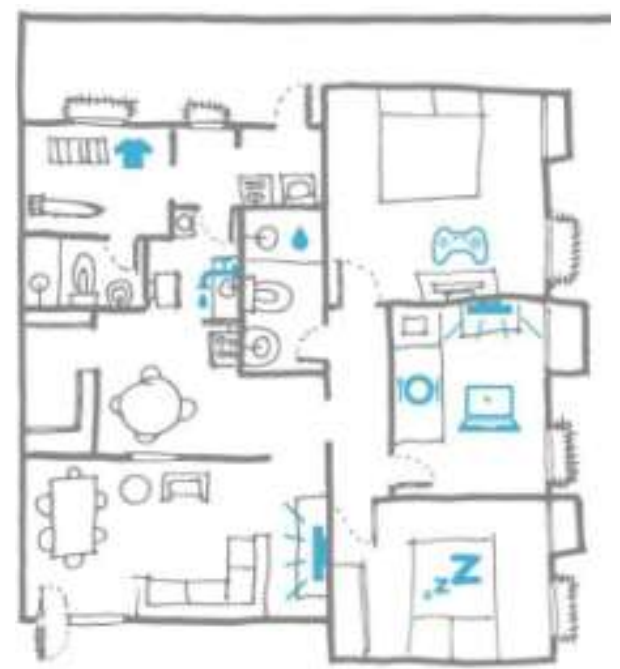

Fonte: Elaborado pelas autoras

Quadro 3 - Síntese da família B.

\begin{tabular}{|c|c|c|}
\hline AMBIENTE & MOBILIARIO & OBSERVAÇOES \\
\hline $\begin{array}{l}\text { QUARTO } \\
\text { DELE(A) }\end{array}$ & $\begin{array}{l}\text { Cama } \\
\text { Mesa e prateleiras } \\
\text { Guarda Roupa }\end{array}$ & $\begin{array}{l}\text { Faz as refeiçōes na cama e fica } \\
\text { bastante tempo no computador. }\end{array}$ \\
\hline $\begin{array}{l}\text { SALA DE ESTAR } \\
\text { E JANTAR }\end{array}$ & $\begin{array}{l}\text { Rack com enfeites } \\
\text { TV e sofá } \\
\text { Mesa de } 6 \text { lugares com vaso } \\
\text { Mesinha de apoio com abajur } \\
\text { Poltrona }\end{array}$ & $\begin{array}{l}\text { O vaso da mesa de jantar é de } \\
\text { vidro. }\end{array}$ \\
\hline BANHEIRO & $\begin{array}{l}\text { Vaso sanitário } \\
\text { Pia } \\
\text { Box de vidro }\end{array}$ & $\begin{array}{l}\text { Toma banho sozinha na maioria } \\
\text { das vezes. Todos os produtos säo } \\
\text { acessiveis. }\end{array}$ \\
\hline $\begin{array}{l}\text { COZINHA E } \\
\text { ÁREA DE SERVIÇO }\end{array}$ & $\begin{array}{l}\text { Geladeira, fogão e gelágua } \\
\text { Pia e bancada } \\
\text { Armários altos } \\
\text { Mesa de vidro (rachado) } \\
\text { Máquina de lavar } \\
\text { Tanque de lavar roupa }\end{array}$ & $\begin{array}{l}\text { Auxilia nas atividades domésticas, } \\
\text { como lavar louça e estender as } \\
\text { roupas. Muitos obstáculos, } \\
\text { caminho sinuoso. }\end{array}$ \\
\hline $\begin{array}{l}\text { QUARTO } \\
\text { DOS PAIS }\end{array}$ & $\begin{array}{l}\text { Cama de casal } \\
\text { Ar condicionado } \\
\text { Guarda roupa }\end{array}$ & Dorme com os pais. \\
\hline $\begin{array}{l}\text { QUARTO } \\
\text { DO IRMÃO }\end{array}$ & $\begin{array}{l}\text { Cams, guarda roupa } \\
\text { Videogame }\end{array}$ & $\begin{array}{l}\text { Assiste o irmäo jogando } \\
\text { videogame. }\end{array}$ \\
\hline
\end{tabular}

Fonte: Elaborado pelas autoras

\subsection{Família C}

Composta por quatro pessoas e um cachorro, a família $\mathrm{C}$ tem um adulto de 32 anos com autismo, que mora com a mãe, o irmão mais velho e a irmã mais nova há 15 anos nesse apartamento térreo de um edifício. A casa possui ambientes bem definidos, porém com muitos móveis e cores escuras. O local preferido da pessoa com transtorno é seu quarto, mais especificamente, a sua cama, onde não permite que ninguém deite e onde dorme sozinho sem dificuldades. 


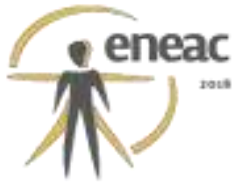

Devido ao seu grau de autismo e seu desenvolvimento no decorrer da vida, ele é incapaz de falar verbalmente e não tem motricidade suficiente para aprender a língua dos sinais, então encontrou outra forma de se comunicar com a família, através de sons produzidos ao bater nos móveis. Portanto, a maioria dos móveis são degradados ou remendados devido a repetição das batidas ou até mesmo pela força que nem mesmo ele tem noção. Isso possibilita riscos mecânicos em todos os ambientes da residência.

Foi instalada uma tranca na porta do banheiro, pois o adulto com autismo estava acordando de madrugada e indo tomar banho sozinho. O box de vidro do banheiro foi removido devido ao pouco espaço e maior facilidade ao dar banho nele, para evitar que ele quebrasse o vidro devido às constantes batidas. A janela do banheiro também foi removida pelo mesmo motivo e substituída por cobogó. Essas medidas já demonstram adaptações na residência em função da pessoa com transtorno mental, mostrando cuidado e aparatos arquitetônicos no dia a dia. Ainda sobre o banho, todos os utensílios precisam ser guardados, pois ele jogavaos pela janela, no vaso sanitário e na pia.

A pessoa com transtorno da família $C$ demonstrou muita limitação quanto à percepção do perigo de suas atitudes, como por exemplo, jogar louça no chão por atenção, pegar comida na panela mesmo com o fogo aceso, bater na janela de vidro para se comunicar, entre outras situações, ocasionando riscos mecânicos.

\section{Figura 7 - Imagem do armário da cozinha danificado e do quarto da pessoa com autismo}

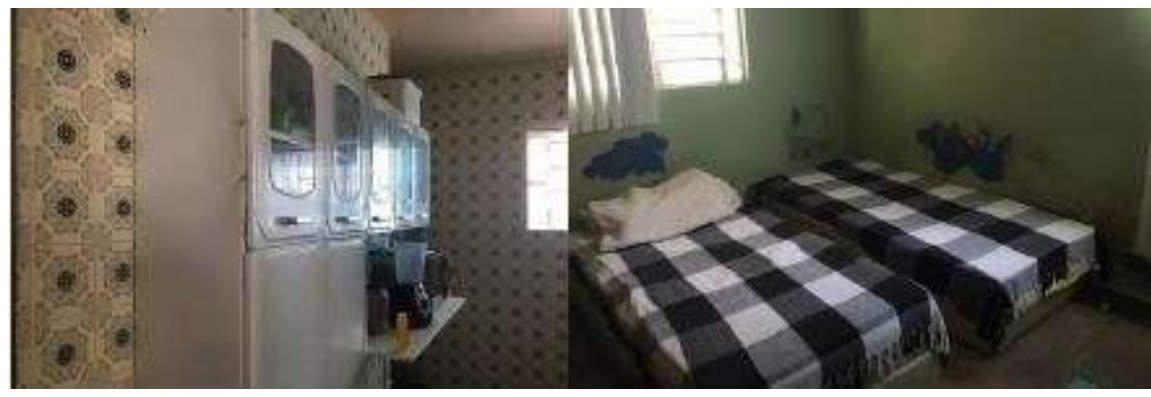

Fonte: Marina Vasconcelos, 2017.

Figura 8 - Mapa de riscos da residência da Família C.

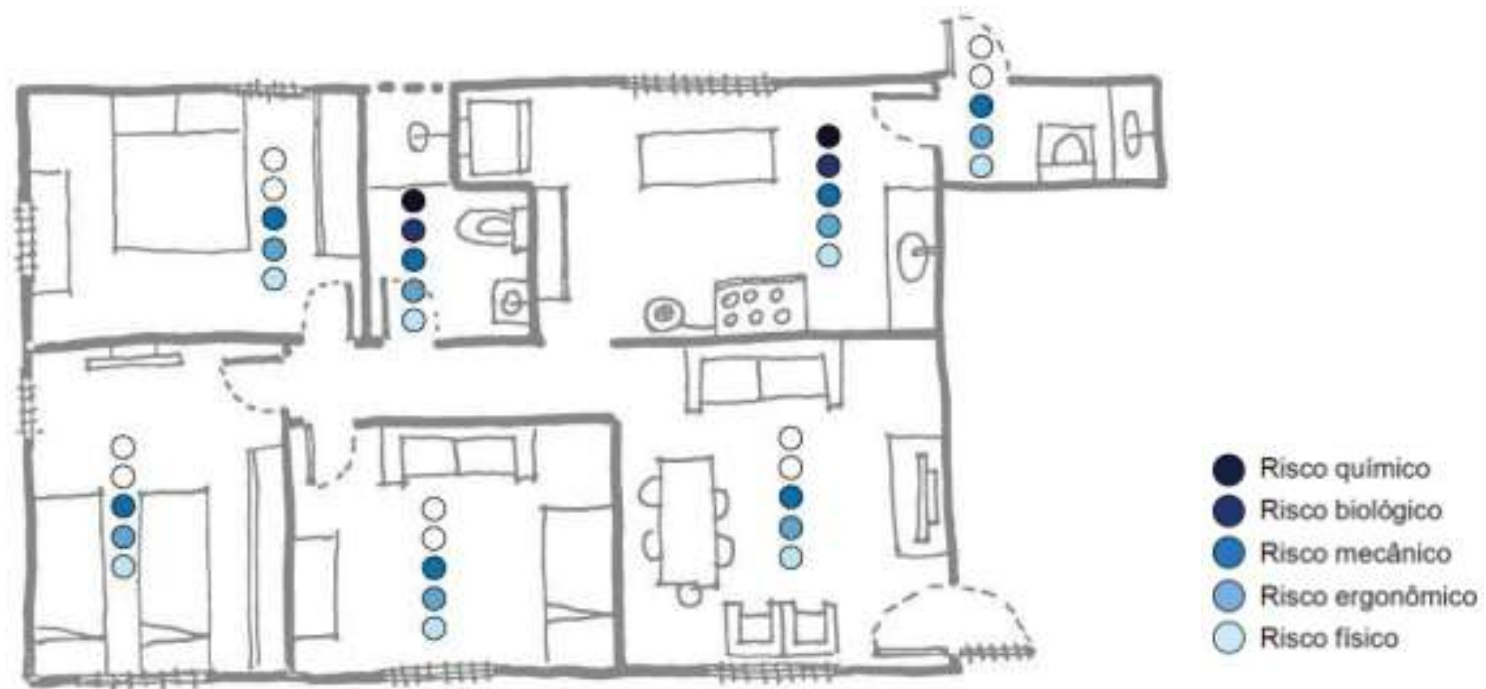

Fonte: Elaborado pelas autoras 


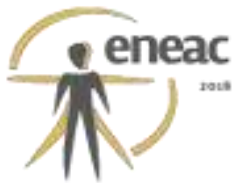

Devido à baixa motricidade apresentada pelo adulto com autismo, ocorreram dois episódios de tropeços no tapete da cozinha, porém o tapete foi mantido, o que possibilita futuros riscos mecânicos. Devido ao seu tamanho e peso, a família tem dificuldades de empurrá-lo quando está sentado na cadeira, quebrando assim vários móveis, aranhando o piso e exigindo esforço físico dos familiares, possibilitando riscos ergonômicos.

A pessoa com transtorno apresentou várias manias e hábitos repetidos, classificados como TOC (Transtorno Obsessivo Compulsivo), como usar o mesmo modelo de roupa para determinadas ocasiões, exemplo, o tênis é apenas para fazer a educação física, a bermuda é apenas para sair e o short de malha é apenas para casa, ou até mesmo levantar e bater no móvel da cozinha e voltar para a sala em certos intervalos de tempo.

Seu café da manhã é servido sempre na cama, o almoço é servido sempre na mesa e o jantar é alternado. Não divide o sofá com ninguém e caso alguém sente no sofá, ele sai e senta no chão. Tem horário para assistir o desenho animado e reclama se alguém desligar a televisão.

\section{Figura 9 - Mapa das atividades da pessoa com transtorno mental}

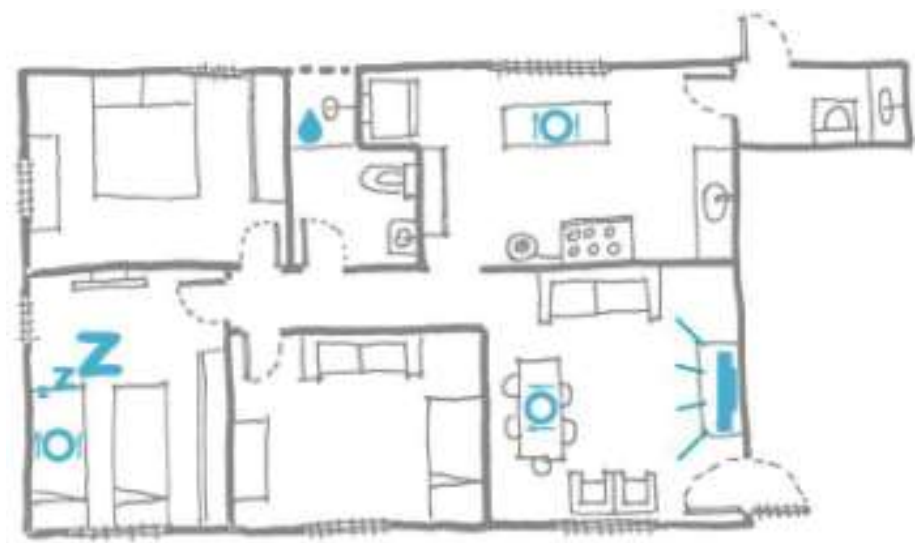

Fonte: Elaborado pelas autoras

Quadro 4 - Síntese da família C.

\begin{tabular}{|c|c|c|}
\hline AMBIENTE & MOBILIARIO & OBSERVACOES \\
\hline $\begin{array}{l}\text { QUARTO } \\
\text { DELE(A) }\end{array}$ & $\begin{array}{l}2 \text { camas de soltairo } \\
\text { Televisîo } \\
\text { Guarda Roupa } \\
\text { Ar condicionado }\end{array}$ & $\begin{array}{l}\text { Recebe o café da manhă na cama. } \\
\text { Divide o quarto com o irmão mais } \\
\text { valho. }\end{array}$ \\
\hline $\begin{array}{l}\text { SALA DE ESTAR } \\
\text { E JANTAR }\end{array}$ & $\begin{array}{l}\text { Rack com enfeites } \\
\text { TV e sofá } \\
\text { Mesa de } 6 \text { lugares } \\
2 \text { poltronas }\end{array}$ & $\begin{array}{l}\text { Näo permite que ninguém fique } \\
\text { no sofá com ele. }\end{array}$ \\
\hline BANHEIRO & $\begin{array}{l}\text { Vaso sanitário } \\
\text { Pia } \\
\text { Sem box e janela }\end{array}$ & $\begin{array}{l}\text { Toma banho acompanhado e } \\
\text { precisa retirar todos os utensilios } \\
\text { e há uma tranca na porta. }\end{array}$ \\
\hline $\begin{array}{l}\text { COZINHA E } \\
\text { ÁREA DE SERVIÇO }\end{array}$ & $\begin{array}{l}\text { Geladeira, fogāo e mesa } \\
\text { Pia e bancada } \\
\text { Armários altos } \\
\text { Máquina de lavar } \\
\text { Tanque de lavar roupa }\end{array}$ & $\begin{array}{l}\text { Precisa ter alguém na cozinha } \\
\text { sempre que cozinhar porque ele } \\
\text { pega comida do fogăo. }\end{array}$ \\
\hline $\begin{array}{l}\text { QUARTO } \\
\text { DAMĂE }\end{array}$ & $\begin{array}{l}\text { Cama de casal } \\
\text { Mesa } \\
\text { Guarda roupa }\end{array}$ & Näo entra. \\
\hline $\begin{array}{l}\text { QUARTO } \\
\text { DA IRMA }\end{array}$ & $\begin{array}{l}\text { Cama e sofá } \\
\text { Guarda roupa } \\
\text { Mesa }\end{array}$ & Não entra. \\
\hline
\end{tabular}

Fonte: Elaborado pelas autoras 


\section{(ame $^{\text {reme }}$}

\section{CONSIDERAÇÕES FINAIS}

A análise desenvolvida nas três residências, com a aplicação de ferramentas da ergonomia e arquitetura, contribui de forma significativa para a compreensão, a assimilação e análise das necessidades específicas da pessoa com transtorno mental em sua residência, como também dos demais membros da família. As visitas realizadas às residências com a presença dos usuários que vivenciam cotidianamente o espaço em estudo é fundamental para o reconhecimento da área e proposta de diretrizes projetuais, como por exemplo, as ilustradas nas Figuras 10 e 11, e proposta de projeto arquitetônico.

Figura 10 - Croqui com diretrizes para a Família A

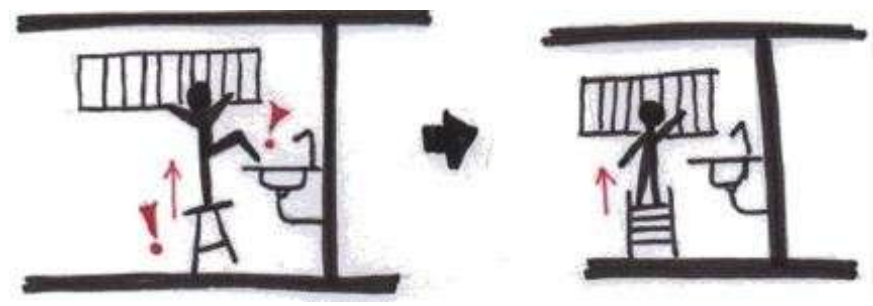

Figura 11 - Croqui com diretrizes para a Família C

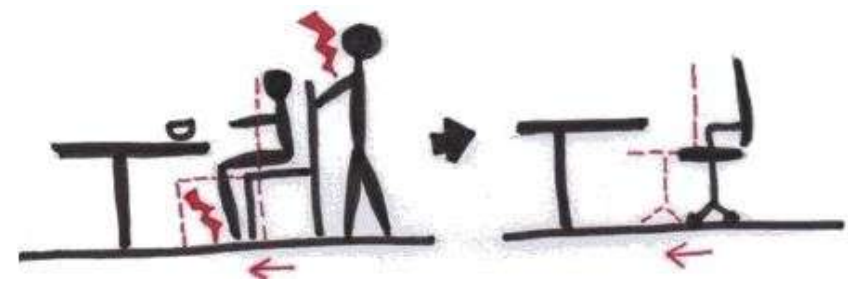

\section{REFERÊNCIAS BIBLIOGRÁFICAS}

AMARAL, O. L. et al. Transtornos mentais. São Paulo: Fundação Djalma Guimarães, 2003.

ASSOCIAÇÃO BRASILEIRA DE NORMAS TÉCNICAS. NR 9: Programa de prevenção de riscos ambientais. Rio de Janeiro, 1978.

ASSOCIAÇÃO BRASILEIRA DE NORMAS TÉCNICAS. NBR 9050: Acessibilidade a edificações, mobiliário, espaços e equipamentos urbanos. Rio de Janeiro: ABNT 2015.

BASTOS, C. S. Avaliação pós-ocupação e design de interiores: uma experiência didática. Dissertação. Natal, 2015.

DALGALARRONDO, P. Sensopercepção e suas alterações. In: Psicopatologia e semiologia dos transtornos mentais. 2ed. Porto Alegre: Artmed, 2008.

FALCÃO, C. S.; SOARES, M. M. Ergonomia e análise multidisciplinar do ambiente construído. Anais III Encontro nacional de ergonomia do ambiente construído e iv seminário brasileiro de acessibilidade integral - ENEAC, p. 1-7, 2011.

FERREIRA, A. B. de H. Dicionário Aurélio da Língua Portuguesa. 5.ed. Rio de Janeiro: Editora Positivo Livros, 2014

FREITAS-SILVA, L. R., ORTEGA, F. A determinação biológica dos transtornos mentais: uma discussão a partir de teses neurocientíficas recentes. Cadernos de Saúde Pública, v. 32, n. 8, p. $1-11,2016$. 